\title{
Orchestrating Mathematical Classroom Discourse About Various Solution Methods: Case Study of a Teacher's Development
}

\author{
Chris Kooloos $(\mathrm{D})$ Helma Oolbekkink-Marchand $(\mathrm{D}) \cdot$ Rainer Kaenders • \\ Gert Heckman
}

Received: 21 December 2018 / Accepted: 1 October 2019 / Published online: 15 November 2019 (C) The Author(s) 2019

\begin{abstract}
Developing and orchestrating classroom discourse about students' different solution methods is an essential yet complex task for mathematics teachers. This study reports on the first stages of classroom discourse development of one Dutch higher secondary school mathematics teacher who had no prior experience in including classroom discourse in her teaching practice. Four lessons in analytic geometry were developed iteratively, in collaboration with the teacher. The lessons consisted of students working on a mathematical problem plus classroom discourse concerning students' different solution methods. Classroom discourse video recordings were collected and analyzed in order to develop a framework to characterize the teacher's actions, and to describe the change in the teacher's role in classroom discourse. The results reveal three main changes in the teacher's role: First, the way the teacher reacted to correct or incorrect solution methods shifted from confirming or setting aside suggestions, toward making the solution methods the subject of discussion; second, the distribution of turns changed such that more students were involved in the discourse and in reacting to each other's solution methods; third, the teacher's actions shifted from convergent, teacher-led actions toward divergent, student-led actions. These results show that within four lessons, an important step has been taken toward establishing a discourse community.
\end{abstract}

C. Kooloos $(\bowtie) \cdot$ H. Oolbekkink-Marchand

Radboud Teachers Academy, Radboud University Nijmegen, Erasmusplein 1, 6525 HT Nijmegen,

The Netherlands

E-Mail: c.kooloos@docentenacademie.ru.nl

R. Kaenders

Mathematical Institute, University of Bonn, Endenicher Allee 60, 53115 Bonn, Germany

G. Heckman

Department of Mathematics, Radboud University Nijmegen, 9010, 6500 GL Nijmegen, The

Netherlands 
Keywords Classroom discourse - Interaction - Multiple solution methods · Upper secondary education $\cdot$ Professional development

\section{Mathematische Diskurse über verschiedene Lösungsmethoden im Klassenraum ermöglichen: Fallstudie zur Entwicklung einer Lehrperson}

Zusammenfassung Mathematische Diskurse im Klassenraum zu verschiedenen Lösungsmethoden von Schülerinnen und Schülern zu entwickeln und zu ermöglichen ist eine wichtige und sicher komplexe Aufgabe für Mathematklehrerinnen und -lehrer. Diese Studie berichtet von den ersten Schritten der Entwicklung einer Unterrichtsgestaltung einer niederländischen Mathematik-Lehrperson in der Sekundarstufe II, die keine Vorerfahrungen hatte, solche Diskurse in ihre Unterrichtspraxis zu integrieren. Vier Stunden zur analytischen Geometrie wurden sukzessive in Zusammenarbeit mit der Lehrperson entwickelt. Die Stunden sahen vor, dass Schülerinnen und Schüler an einer mathematischen Aufgabe arbeiteten und darüber hinaus einen Diskurs über verschiedene Schülerlösungen führten. Videoaufnahmen dieser Diskurse im Klassenraum wurden zusammengestellt und analysiert, um einen Rahmen zu entwickeln, die Handlungen der Lehrperson zu charakterisieren und die Veränderungen in der Lehrerrolle in Bezug auf solche Diskurse im Klassenraum zu beschreiben. Die Ergebnisse offenbaren drei wesentliche Veränderungen in der Lehrerrolle: Erstens, die Art und Weise, in der die Lehrperson auf richtige oder fehlerhafte Lösungen reagierte, verschob sich von Bestätigung oder dem Geben von Hinweisen dahin, die Lösungsmethoden zum Gegenstand der Diskussion zu machen; Zweitens, änderte sich der Unterricht dahingehend, dass mehr Schülerinnen und Schüler zu Wort kamen und wechselseitig auf die jeweiligen Lösungsmethoden reagierten; Drittens veränderten sich die Lehreraktivitäten von konvergenten, lehrergeleiteten Handlungen zu divergenten, schülergeleiteten Handlungen. Diese Ergebnisse zeigen, dass innerhalb von vier Stunden wichtige Schritte in Richtung der Etablierung einer Diskursgemeinschaft gegangen werden können.

Schlüsselwörter Diskurs im Klassenraum · Interaktion · Vielfältige Lösungsmethoden · Sekundarstufe II · Lehrerfortbildung

\section{Introduction}

In mathematics education, students should learn to think mathematically. This involves more than merely being able to solve routine tasks. Polya (1957) states that a teacher should not drill students in routine operations, but rather assign them appropriate problems and help them to solve those problems. What distinguishes a problem from a task is the lack of "easy access to a procedure for solving the problem" (Schoenfeld 1985, p. 11). For most mathematical problems and tasks, several different solution methods are possible; whenever a group of students is confronted with a mathematical problem, students have differing ideas and find various solution methods. This requires that teachers shape their lessons such that 
students "use each other as resources for working through those problems, and then share their strategies and solutions in whole-class discussions" (Stein et al. 2008, p. 315).

Orchestrating classroom discourse that builds on students' thinking and also advances students mathematically is extremely challenging (e.g., Nathan and Knuth 2003; Sherin 2002). In whole-class discussions, the role of the teacher is crucial. How mathematics teachers can develop and orchestrate classroom discourse remains an important question for research, especially regarding various solution methods for mathematical problems in higher secondary school. Even though both scholars and policymakers advocate the inclusion of classroom discourse in mathematics educational practice, many mathematics teachers do not orchestrate classroom discourse at all, or if they do, they do not transcend patterns such as "initiation-responseevaluation" (Cazden 2001) or "show and tell" (Stein et al. 2008). Furthermore, most studies examining or describing classroom discourse focus on primary school or lower secondary school (Walshaw and Anthony 2008). The tasks and problems discussed in primary or lower secondary school usually take only a few steps to solve, whereas problems in higher secondary school are more complex and require several steps to solve. Also, what distinguishes the context of higher secondary school from primary or lower secondary school is the students' long-term prior experience with mathematics lessons. In the Netherlands, national standardized testing, widespread reliance on textbooks (Blockhuis et al. 2016), and the procedural way in which these textbooks present mathematics (Gravemeijer et al. 2016) lead to most students attending years of outcome-oriented mathematics lessons. By the time students reach the tenth grade they have hardly experienced or been involved in wholeclass discussions that incorporate various solution methods.

In order to investigate the development of classroom discourse in higher secondary school, the first author collaborated with a tenth-grade mathematics teacher to iteratively develop four analytic geometry lessons. For the teacher as well as the students, both the subject of analytic geometry and the set-up of the lessons based on classroom discourse were new. The current presentation of analytic geometry in the textbooks is very procedural and often consists of step-by-step instructions. For example, to calculate the distance from a point to a line, only one solution method is given. Generally, students are accustomed to memorizing and practicing such stepby-step procedures. In our study, instead of providing students with a single procedure, the teacher presented them with open problems, and orchestrated classroom discourse about students' different solution methods. When students were asked to calculate the distance from a point to a line, several possible solution methods were formulated and discussed. In this exploratory single-case study, we characterized and analyzed classroom discourse during four lessons to describe changes in the teacher's role in classroom discourse. 


\section{Theoretical Framework}

\subsection{Classroom Discourse}

Solving mathematical problems and discussing various solution methods is an important part of learning mathematics. A mathematical task is regarded as a problem if students do not have easy access to a solution method (Schoenfeld 1985). Most problems can be solved in more than one way. Learning how to solve problems in multiple ways is associated with developing problem-solving skills and mathematical thinking, because students become flexible in choosing among strategies (Heinze et al. 2009). Furthermore, Leikin and Levav-Waynberg (2012) argue that solving geometry problems in a variety of ways fosters students' knowledge and creativity. Additionally, a teacher may gain insight into "the students' conceptual possibilities and current understandings" (Yackel and Cobb 1996, pp. 466-467) through an emphasis on student descriptions of their different solution methods. Moreover, by comparing various solution methods, students can be supported in making important mathematical connections between different representations (Heinze et al. 2009).

By carefully planning and orchestrating classroom discourse, teachers can guide their students in connecting a variety of solution methods and in discussing important mathematical ideas (Stein et al. 2008). Classroom discourse about variations in students' solution methods that maintains focus on student ideas provides students with rich mathematical learning opportunities (Murata et al. 2017). Effective orchestration of classroom discourse shifts students' cognitive attention from problem solutions and procedural rules to sense-making and the reasoning that leads to a solution (Yackel and Cobb 1996).

Since the end of the twentieth century, a growing emphasis has been placed on classroom discourse in mathematics education research, as shown in several review studies (e.g., Herbel-Eisenmann et al. 2017; Ryve 2011). Whether the perspectives are interactionist, cognitivist, socio-constructivist, or thinking-as-communicating, the research community seems to agree that classroom discourse concerning student ideas should be an important part of mathematics lessons. Sfard articulates this as "the question is not whether to teach through conversation, but rather how" (Sfard et al. 1998, p. 50).

Ryve (2011) states that researchers should be clear about their definition of discourse. Classroom discourse has been defined, investigated and described in a variety of studies, sometimes under different names-for example, exploratory talk (Mercer and Sams 2006), classroom dialogue (Scott et al. 2006), or (whole-class) discussions (Richards 1991; Stein et al. 2008). We join this field of research and choose to employ as our definition of (mathematical) classroom discourse: verbal interaction among teacher and students as a community, in which students' ideas about mathematical problems or tasks are discussed. By productive (mathematical) classroom discourse, we mean discourse that builds upon students' ideas, and advances the students mathematically_in particular, toward certain disciplinary ideas. We define a discourse community as a class in which productive classroom discourse is a regular course of action. 
Important criteria of classroom discourse include that students participate, that the discussion is built upon students' ideas and reasoning, that truth is collaboratively established based upon logical argumentation, and that students are guided toward disciplinary mathematical ideas.

A prerequisite to enable a whole-class discussion is that students participate, meaning they should talk to share their thinking in an understandable manner as well as listen and try to understand each other. Ideally, all students try to follow what is being said and indicate if something is unclear to them. O'Connor et al. (2017) found that whereas participating in discourse-based instruction does support mathematical learning of the whole group, on an individual level the amount of words spoken by students does not necessarily predict their learning. They conclude that once a discourse community has been established, listening carefully without talking may also constitute active participation in classroom discourse.

Classroom discourse is initially described as a way to align classroom mathematics with mathematics as a discipline in which mathematical meaning is negotiated. Lampert (1990, p. 42) perceives mathematics discourse as being "about figuring out what is true, once the members of the discourse community agree on their definitions and assumptions". In other words, instead of trying to get the right answer, mathematical discourse is about trying to understand and question each other's ideas and reasoning and collaboratively deciding what is true based on logical argumentation. Engle and Conant (2002) describe that providing students with opportunities for disciplinary engagement involves letting them engage in genuine problem-solving, giving them authority in addressing such problems, and holding them accountable to others and to disciplinary norms. Students are held accountable to the community of learners by sharing and discussing their ideas, accountable to standards of logical argumentation, and accountable to disciplinary knowledge insofar as their work and discussions relate to the rules of mathematics as a discipline (Michaels et al. 2008).

Another essential criterion for productive classroom discourse is that students should be guided toward certain disciplinary mathematical ideas. For classroom discourse to be productive, students sharing and discussing ideas is not sufficient. Some students' mathematical ideas are more advanced than others, some explanations are generalizable, and some are not. Here lies an essential yet challenging task for the teacher, namely orchestrating classroom discourse such that the students are supported in making important mathematical connections and guided toward disciplinary ideas, while maintaining the focus on students' ideas and reasoning (Stein et al. 2008).

\subsection{The Teacher's Role in Classroom Discourse}

For classroom discourse, the teacher's role is crucial. However, orchestrating productive classroom discourse is a complex and extremely challenging task for most teachers (e.g., Nathan and Knuth 2003; Sherin 2002). The most common form of classroom discourse is referred to as the "initiation-response-evaluation" pattern: the teacher initiates a question, a student responds, and the teacher evaluates the response (Cazden 2001; Mehan 1979). Drageset (2015) describes a similar pattern of a teacher asking closed questions and students giving "teacher-led responses", i.e. 
responses that the teacher almost provided for them-thus sharing little information about students' thinking. These patterns do not meet the criteria for classroom discourse elaborated above, because they challenge students to try to guess what their teacher is thinking instead of building on and deepening students' thinking. Shifting from teacher-centered toward student-centered teaching requires a renegotiation of classroom norms and appropriate teacher practices.

The teacher's role is crucial in developing classroom discourse that meets the criteria described above: First of all, the teacher needs to get students to participate, with students needing to talk, and more specifically, students must explain their thinking; second, the teacher must get students to listen to each other and to respond to each other's ideas and reasoning, in order to create a discussion based on students' ideas and reasoning; third, the teacher needs to hold students' talk accountable to logical argumentation; finally, the teacher needs to guide the students toward disciplinary ideas. Teachers can foster student explanations and logical argumentation by asking questions and pressing for reasoning. Asking for explanations is generally considered a productive teacher practice in mathematics education research as well as in cognitive science (Star and Verschaffel 2017). Specific teacher actions or "talk moves", such as asking students to restate another student's words or asking students to apply their own thinking to someone else's thinking, can support teachers in building a discussion and ensuring accountability (Michaels and O'Connor 2015; Smith and Stein 2018).

Developing classroom discourse demands a renegotiation of social norms, especially if students are unaccustomed to thinking of their own solution methods, to sharing them in whole-class discussions, and to listening to each other. By asking for explanations and getting students to respond to each other, teachers implicitly negotiate favorable norms. In addition, teachers can explicitly state and discuss rules for communication. This is what Cobb et al. (1993, p. 99) call "talking about talking about mathematics". In such a meta-discussion, the teacher's role can be different than in the discussion concerning students' solution methods. For example, Cobb et al. (1993) describe how a teacher who involved students in negotiation of meaning when talking about mathematics took a more directive role when talking about talking about mathematics. In addition to negotiating social norms, Yackel and Cobb (1996) describe how negotiating sociomathematical norms (e.g., what counts as a mathematical justification or what counts as a mathematically different solution method) is inherent in classroom discourse and strongly influences the mathematical disposition of students. More recently, Güçler (2016) used Sfard's concept of metadiscursive rules (Sfard 2008) to show that making these rules explicit in discussion fosters students' mathematical learning.

What makes the orchestration of productive classroom discourse particularly complex is finding balance between building on students' ideas and guiding the students toward disciplinary ideas (Stein et al. 2008). Various studies have described the difficulties that teachers may experience in finding balance between being open to student ideas and achieving certain mathematical goals (e.g., Cengiz et al. 2011; Nathan and Knuth 2003; Sherin 2002). Teachers who develop student-centered classroom discourse may feel the need to refrain from all content-related responses or evaluative statements, in order to build the discussion on student ideas. However, the teacher, 
as a representative of the mathematics community, has the responsibility to make decisions about the ideas students share and to advance the mathematical learning of the whole group toward certain disciplinary mathematical ideas (Yackel and Cobb 1996). Making such decisions requires that the teacher listens to students and understands their thinking. Understanding what students mean when they talk about mathematics is a complex task (Wallach and Even 2005), and identifying students' mathematical thinking to build on during classroom discourse is even more complicated (Van Zoest et al. 2017). Orchestrating classroom discourse that advances the mathematical learning of students requires very specific teacher knowledge, such as pedagogical content knowledge (Shulman 1986) and specialized content knowledge (Ball et al. 2008; Speer and Wagner 2009).

Previous case studies have investigated various aspects of professional development of mathematics teachers who succeeded in orchestrating productive classroom discourse or were making extraordinary progress in their development (e.g., Hufferd-Ackles et al. 2004; Leinhardt and Steele 2005; McClain and Cobb 2001). Sherin (2002) describes how a teacher gradually shifted his attention to process: fostering students contributions and discussion; and content: choosing particular mathematical ideas to pursue, and provides a filtering model for achieving a balance between the process and the content of classroom discourse. Stein et al. (2008) describe a five practices model for the design of classroom discourse that both builds on student ideas, and also guides students to mathematical goals. The five practices-anticipating, monitoring, selecting, sequencing, and connecting-should be carefully prepared to reduce complexity and in-the-moment decision making during classroom discourse. Working through these practices involves considerable domain-specific work. The complexity, as well as the mathematical work of teaching student-centered mathematics lessons, was recently described by Ball (2017). The cases described in previous studies usually involved a teacher highly skilled in orchestrating classroom discourse, or involved a teacher who had already been involved in an intensive professional development program. However, there seems to be a consensus that orchestrating classroom discourse should be part of every mathematics teacher's practice.

\subsection{Research Questions and Aims}

In this study, the researcher collaborated with one teacher, Anna, and developed classroom discourse about various solution methods. Unlike previous studies that have described the practice of teachers who are highly skilled or experienced with regard to productive classroom discourse, or that have described a longitudinal process of development, Anna had no prior experience with classroom discourse in the sense of students discussing a variety of solution methods. In this study, we focused on the beginning of her development with regard to classroom discourse, in order to observe what could be achieved within a relatively short period of time. We report on classroom discourse about students' solution methods in four analytic geometry lessons in higher secondary school. This provides a counterpoint to previous studies, in which classroom discourse has been investigated in elementary mathematics lessons in primary school or lower secondary school (e.g., Drageset 
2015; Henning et al. 2012; Nathan and Knuth 2003; Sherin 2002). Our design for classroom discourse focused on encouraging students to share their ideas and articulate their thinking through particular kinds of teacher actions in classroom discourse. Based upon previous research (Drageset 2015; Henning et al. 2012) and our collected data, we developed a framework for analyzing teacher actions during classroom discourse, and this framework was in turn used to describe changes in the teacher's role in classroom discourse throughout the four lessons.

The research questions are as follows:

1. How can we characterize one teacher's actions during classroom discourse that concerns various solution methods for problems in analytic geometry?

2. What changes can be discerned in the teacher's role in classroom discourse about various solution methods?

\section{Methodology}

Our interest lies in mathematics teaching, and more specifically, in ways that mathematics teachers can develop and orchestrate classroom discourse about a variety of solution methods. We conducted an exploratory case study to enable an in-depth investigation of changes in classroom discourse of a secondary school teacher who is new to orchestrating classroom discourse. In this case study, a Dutch mathematics teacher and a researcher collaboratively developed lessons in iterative design cycles. Video data collected during enactment of the four lessons were qualitatively analyzed to answer the research questions.

\subsection{Context}

One teacher together with one researcher collaboratively developed four discoursebased analytic geometry lessons. Anna ${ }^{1}$, the teacher, works at a secondary school in a medium-sized city in the Netherlands. At the time of this study, she had had more than 30 years' experience teaching mathematics. The researcher, who is also the first author of this paper, combined his work as a $\mathrm{PhD}$ researcher with his work as a teacher of secondary school mathematics. During the 2016-2017 school year, both Anna and the researcher participated in a Teacher Design Team (TDT) at Radboud University Nijmegen. The topic of the TDT was analytic geometry, a new subject in the Dutch curriculum for higher secondary school. The discussions in the TDT were mainly content-related: problems were solved and solution methods were discussed. Problems in analytic geometry often allow for multiple solution methods involving different representations, particularly geometric and algebraic representations. Like the researcher, Anna was interested in teaching such that students' different solution methods are discussed in the classroom. Therefore, Anna and the researcher decided to start an intensive collaboration in order to develop classroom discourse that concerns variations in solution methods. Anna had enacted one analytic geometry

\footnotetext{
1 The teacher's name and all students' names are pseudonyms.
} 


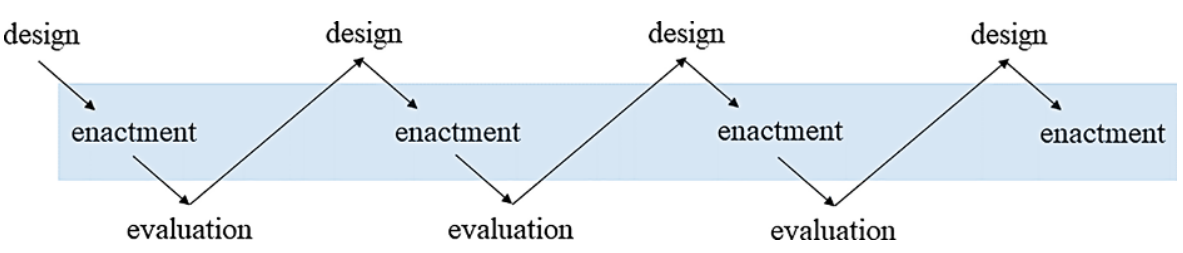

Fig. 1 Iterative development of four lessons

lesson, based on discussions in the TDT, in which she orchestrated classroom discourse about a variety of students' solution methods for the first time. Anna and the researcher took this lesson as the starting point for their collaboration, and together they developed three more analytic geometry lessons for the same tenth-grade class (ages 15-16) of the pre-university science track at Anna's school. Together, these four lessons constituted the case that was investigated for this study. The study lasted from February, 2017 through July, 2017. The time span between consecutive lessons was one month for lessons 1 and 2, two months for lessons 2 and 3, and two weeks for lessons 3 and 4. Parents gave their passive consent for videotaping the lessons. Following a design-based research structure, the lessons were developed in iterative cycles (Cobb et al. 2003).

As visualized in Fig. 1, the lessons were developed in systematic consecutive phases of design, enactment, and evaluation. The enactment phases are the actual lessons, and the classroom discourse during the enactment phases constituted the object of this study. Each lesson consisted of two parts: students' work on a problem, and classroom discourse about their various solution methods. During enactment phases, the researcher observed, took field notes, and filmed video recordings of classroom discourse. All design and evaluation phases took place in meetings between Anna and the researcher, except the first design phase which took place in the context of the TDT. For each of the lessons, Anna's main goal was to orchestrate classroom discourse about various students' solution methods.

In the design phase, Anna and the researcher chose an appropriate problem and discussed the lesson plan. In designing the lesson, main focus was on orchestrating classroom discourse about students' solution methods. The problems were based on tasks from the textbook, yet modified in the sense that students were not provided with a step-by-step procedure: the students were instead challenged to solve the problems according to their own approach. In other words, we made the tasks into genuine problems. The analytic geometry problem chosen for the first lesson is the following:

Problem 1: Calculate the distance from point $P(6,1)$ to line $l: y=\frac{1}{3} x+4$.

This problem involves calculating the distance between a point and a line. In the textbook, rather than presenting this as a problem, students are provided with a stepby-step procedure to calculate the distance between a point and a line. However, we discovered many differing ways of calculating the required distance. Instead of taking students through the steps of the standard procedure, Anna wanted to let the 
students grapple with the relevant mathematics and come up with their own solution methods.

In the evaluation phase, the teacher and researcher watched the video recording of classroom discourse together, and reflected on the lesson. They discussed both student actions and teacher actions: student actions to figure out the students' mathematical thinking, and teacher actions to reflect on their effect on students and to consider possible alternative actions. Additionally, Anna and the researcher discussed the lesson plan and considered adjustments.

The collaboration between Anna and the researcher can be characterized by three central aspects: goal, roles, and topic. First, Anna and the researcher had a shared goal, i.e., developing classroom discourse in Anna's classroom, such that students would share and discuss various solution methods. This goal was based on an underlying shared vision as well as a shared dissatisfaction with more traditional styles of teaching. Second, both Anna and the researcher adopted different roles in the discussions. Anna participated as an expert teacher with more than 30 years' experience, and also as a learning professional, sometimes reflecting on her own practice, and sometimes asking for very specific recommendations concerning teacher actions. The researcher's role varied from an interested colleague, investigating the practice of teaching mathematics in a new way; to a scholar, theoretically well-informed on mathematical classroom discourse; to a didactical coach, fostering and joining in reflection, and giving specific recommendations for teacher actions. Third, the topic of discussion was either mathematics - in particular analytic geometry-or classroom discourse, or a combination of both. For example, problems and their solution methods were discussed, as was student thinking or expectations of students' ideas and activities. The teacher's role in classroom discourse and specific teacher actions formed another important topic of discussion.

\subsection{Data Collection and Preparation}

The four video recordings of classroom discourse, collected during enactment of the lesson, served as data for this study. Field notes were made to guide transcription and analysis. Two cameras were used: One main camera was placed in the back, and one was placed in the front of the classroom to capture which student talked at specific moments. The relevant parts (each with a duration between 21 and $24 \mathrm{~min}$ ) containing classroom discourse were transcribed. All transcripts were linked to specific moments in the video recordings using Atlas.ti software (version 7).

\subsection{Data Analysis}

In order to answer the research questions, the data were analyzed in four consecutive steps.

In the first step, one transcript was coded in an exploratory manner using sensitizing concepts from the theoretical framework, such as various solution methods and social norms. This resulted in a preliminary set of categories. We found that these categories roughly matched the categories of Drageset's framework (2015), which 
was developed to analyze classroom discourse on a turn-by-turn basis through the categorization of student and teacher actions during their interactions.

In the second step, process coding (Saldaña 2016) was used on two transcripts to code the teacher and student actions in classroom discourse, based on Drageset's framework (2015). Although the study focused on teacher actions, the student actions were also coded in order to guide analysis. During the coding process, Drageset's framework was adjusted for two main reasons: First, the framework as developed by Drageset (2015) is based upon discourse in higher primary school that deals with elementary mathematics, namely fractions, whereas the classroom discourse in our data concerned more advanced mathematics in higher secondary school, and more specifically, various solution methods for problems that require several steps to solve. This resulted in some codes being changed, removed, or added to fit the discourse in our data. Examples will be given below. Second, Drageset's categorization of redirecting, progressing, and focusing actions is based on the effect of the teacher's actions on the process of interaction. Redirecting involves changing the course of interaction, progressing involves moving the process forward, and focusing involves pausing the process to enlighten details or deepen the discussion. ${ }^{2}$ In our analysis, we were particularly interested in whether classroom discourse was in line with critical characteristics, as elaborated in the theoretical framework. For example, students should be encouraged to both explicate their thinking and react to each other's ideas. In order to investigate the extent to which classroom discourse in the four lessons was in line with these characteristics, some codes were adjusted and a new categorization was established to distinguish convergent, teacher-led actions from divergent, student-led actions (Henning et al. 2012). This second step of our data analysis is a hybrid form of deductive coding, based on the two existing frameworks and inductive coding that emerged from the data (Saldaña 2016). The coding process resulted in a code manual with instructions for coding and descriptions of all the codes, including illustrative quotes. These code descriptions are presented in Appendix.

We will now give some examples of adjustments that were made during the second step of data analysis, before continuing with the third step of analysis. The framework that resulted from our analysis will be presented in the beginning of the results section below (4.1). Our framework, as explained above, is partially based upon Drageset (2015), but we omitted or added several teacher and student actions. We omitted several teacher actions that we did not find in our data, such as: "apply to similar problems", and "simplification". We added the encouraging actions "confirmation" and "encouragement" because the teacher in our study often interrupted students' solution methods that consisted of several steps, for example by saying "yes", or by repeating the student's last statement. These utterances are regarded as encouraging because they might have been meant to reassure students and invite them to keep talking and further explain their methods. Inviting students to keep talking can be done either in a slightly evaluating manner, by confirming, or in a more questioning manner (for example, "Yes?"), which is regarded as encouraging. We added "external general" and "external specific" to indicate when the teacher

\footnotetext{
${ }^{2}$ For more details, see Drageset $(2014,2015)$.
} 
asked students who were not part of the discourse to react to the solution method being discussed. During the study we realized that asking specific students to react can help in getting all students involved in a discussion, thus leading to a distinction between general and specific. We added the action "rules of classroom discourse" for when the teacher articulated the rules of communication in classroom discourse, a practice that helps establish favorable classroom norms. We added the action "reformulate" to indicate when the teacher reformulated a previous statement. This includes what Drageset (2015) has categorized as "point out": the repetition of a student's statement, usually changing it slightly, in order to clarify or to emphasize important aspects. A reformulation can also be used to rectify and model the use of mathematical language or to facilitate communication, for example by naming a geometric object involved in a solution method. Although Henning et al. (2012) categorize reformulations as divergent, we categorized them as convergent, because in reformulating, the teacher decides what to point out, what to name, or what to clarify. Regarding student actions, we also added, "(steps of) solution methods", to indicate when a student's utterance comprised part of a possible solution method. In most cases, such an utterance was followed by an encouraging action, after which the student continued and finished the solution method. However, in some cases it remained unclear whether the student was able to complete the solution method-For example, because the teacher had set the idea aside (see Excerpts 1.1 and 1.2 below).

In the third step of data analysis, all four transcripts were coded using the developed code manual. All coded utterances were also assigned a second code designed to indicate which person was speaking, to analyze the alternation of turns during the discourse, and the total number of words spoken by the students and by the teacher.

In the fourth step, the coded transcripts were analyzed in order to investigate changes in the teacher's role in classroom discourse. Two Atlas.ti applications were used to generate tables: Word Count, for the total of words spoken by the students and by the teacher; and Codes-Primary Documents Table, for the frequencies of teacher actions throughout the four lessons. Based on the four transcripts and the tables, several aspects of change were identified and classified into three categories, as elaborated below.

To ensure a sufficient quality of data analysis, the first and second author of this paper had a meeting every two weeks to discuss the analysis process. The first author was the main coder. During several steps of data analysis, the second author also coded part of a transcript. Discrepancies were discussed until a consensus was reached, resulting in adjustments to the code descriptions and framework.

\section{Results}

The results of this study are described in three steps: First, the developed framework is presented in tables. Second, quantitative outcomes of analysis are presented in figures. Third, we elaborate on the changes in the teacher's role in classroom discourse, classified into three categories: solution methods, distribution of turns, and teacher actions. 


\subsection{Framework}

We developed a framework for describing the teacher's actions during classroom discourse about variations in solution methods (Tables 1 and 2). This framework is an ordered categorization that can be used to analyze student and teacher actions during interactions, i.e., individual utterances during classroom discourse about students' solution methods. The teacher actions are divided into four main categories: 1) convergent actions, 2) divergent actions, 3) encouraging actions, and 4) regulating actions.

Convergent actions are teacher-led. They indicate that the teacher has control over the ideas being discussed as well as over their evaluation. The teacher demonstrates or reformulates something, sets an idea aside, or asks for closed progress details: for instance a teacher may ask a closed, simple question for which only one correct answer is possible. The teacher often reformulates students' statements in order to add important details or reshape the mathematical language.

Divergent actions are student-led in the sense that they are teacher actions intended to make students' thinking public and to build the discussion on student ideas. The teacher does so by requesting an explanation or a clarification, by asking a particular student ("external directed") or students in general ("external general") to react, or through open progress initiatives; that is, by giving students the opportunity to share their own solution methods, or to further develop a solution method that has been mentioned previously.

Encouraging actions ("confirmation" and "encouragement") are teacher utterances that invite students to continue talking. This can be done in an evaluative manner, by confirming what was just said, or through encouragement without evaluation.

Finally, regulating actions ("rules of classroom discourse") refer to the teacher articulating the rules of communication during classroom discourse.

Regarding students actions, the discourse in our data often consisted of students explaining their solution methods in several steps and the teacher encouraging, confirming, or reformulating the student in between steps. These student actions are "(steps of) solution methods". "Evade answer" refers to students abstaining

Table 1 Teacher actions

\begin{tabular}{lll}
\hline Divergent actions & Convergent actions & Encouraging actions \\
\hline Request explanation (REX) & Demonstration (DEM) & Confirmation (CON) \\
Request clarification (RCL) & Reformulate (REF) & Encouragement (ENC) \\
Open progress initiatives (OPI) & Closed progress details (CPD) & Regulating actions \\
\cline { 2 - 2 } External general (EXG) & Set aside (SEA) & Rules of classroom discourse \\
External directed (EXD) & & (RCD) \\
\hline
\end{tabular}

Table 2 Student actions

\begin{tabular}{ll}
\hline (Steps of) Solution method (ssm) & Evade answer (eva) \\
Explanation (exp) & Remark about solution \\
Partial answer (paa) & method (rsm) \\
Teacher-led response (tlr) & External (ext) \\
& Question (que) \\
\hline
\end{tabular}


from answering. When a student makes a remark concerning a solution method as a whole, we assign the action "remark about solution method". A student action is "external" when it involves a student who was not part of the original interaction, but who makes a remark concerning the content of the discussion. A partial answer is an answer that is not complete, not explained, incomprehensible, or not entirely correct.

\subsection{Overview of the Four Lessons}

The participation of teacher and students in classroom discourse, and the categorization of teacher actions are both illustrated in this section.

Fig. 2 shows that the number of students who contributed to classroom discourse increased during the course of the four lessons. In the fourth lesson, 18 out of 23 students made a contribution to the discourse, which is more than $75 \%$. Fig. 3 shows that the percentage of student utterances greatly increased from the first to the second lesson. In the first lesson, the teacher talked twice as much as the students; in the second lesson, the students talked twice as much as the teacher; and in the third and fourth lessons, the students talked slightly more than the teacher. The following section provides excerpts in which these changes are recognizable from the first and fourth lessons. As shown in Fig. 3, fewer words were spoken in the third lesson. This was due to silent episodes during which students wrote a solution method on the whiteboard.

Fig. 2 Number of students talking in classroom discourse

Fig. 3 Number of words by students and teacher
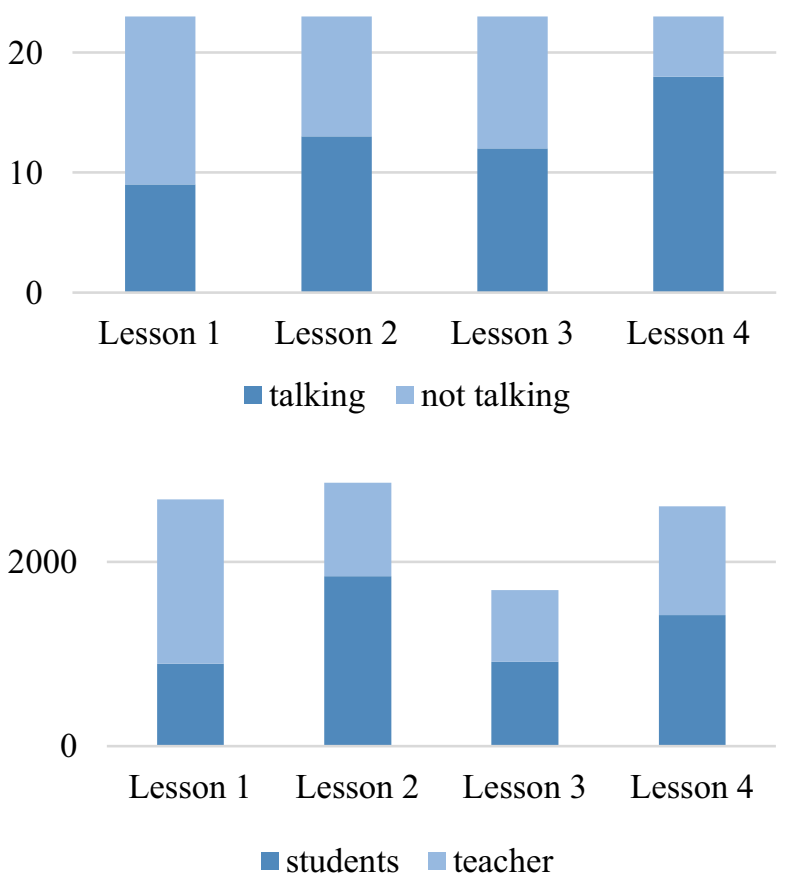


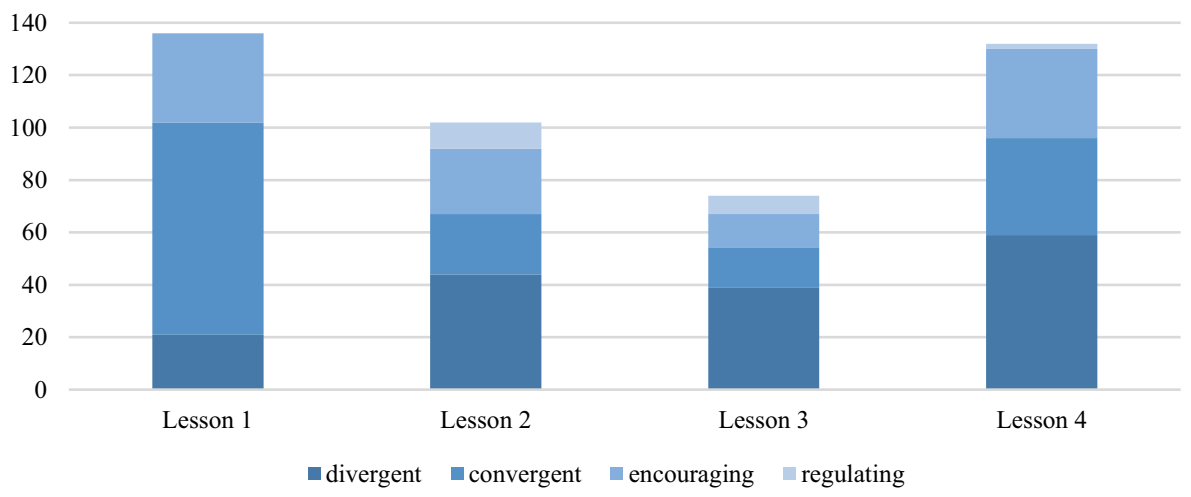

Fig. 4 Frequencies of teacher actions

As displayed in Fig. 4, the relative frequency of divergent actions increased considerably over the course of the four lessons. In particular, Anna requested more explanations (consecutively during the first to the fourth lesson; 3, 6, 3, and, 13) and involved more students in the discussion by means of "external" actions $(3,17,20$, and 29). The convergent actions show a decreasing trend. Most convergent actions were "closed progress details" (44, 13, 4, and 23) or reformulations $(25,8,7$, and 9). In the presentation of qualitative results below, the changes are made visible and described in more detail. Notably, during the first lesson we counted six instances of "demonstrate", during the second and third lessons we counted no instances, and during the fourth lesson only one such instance was observed (see Excerpt 4.3). In the second and third lessons, the teacher frequently used regulating actions to articulate rules for participating in classroom discourse.

\subsection{Change in the Teacher's Role in Classroom Discourse}

The most notable changes in the teacher's role in classroom discourse are divided into three categories, namely: solution methods, distribution of turns, and teacher actions. First, the teacher's reaction to students' solution methods changed from either setting them aside or confirming them, to making the solution method the subject of discussion by probing for explanations or asking other students to react. Second, the distribution of turns changed throughout the four lessons. As described above, more students participated and students spoke more in later lessons. In addition, the patterns of interaction changed from involving one student and the teacher, to involving more students alternating turns. Third, as visualized in Fig. 4 above, the teacher's actions changed from mainly convergent toward mainly divergent. The quantitative results of the coding process appear to show that the main change with regard to teacher actions seemed to be between the first and second lessons. Furthermore, the fourth lesson seemed to deviate slightly from the apparent trend of increasingly divergent and decreasingly convergent actions. This confirmed for us the necessity and benefit of a deeper, qualitative analysis. The qualitative analysis of the four lessons showed a continuing change with regard to all three categories. 
These changes can best be described and illustrated using excerpts of classroom discourse from the first and the fourth lessons.

\subsubsection{Solution Methods}

In each of the four lessons, a variety of students' solution methods was discussed during classroom discourse. A substantial change can be perceived in the way the teacher dealt with correct, incomplete, and incorrect solution methods. During the first lesson, the teacher reacted to incorrect or incomplete solution methods by setting them aside or by demonstrating why they were incorrect, whereas in the fourth lesson, the teacher refrained from commenting on content if a student made a mathematical error; rather, she prompted other students to correct the error. Regarding correct solution methods, we perceive a similar change: during the first lesson, when a student finished giving a solution method, the teacher confirmed the method and moved on. During the second and third lessons, the teacher reacted to correct solutions by asking the class if they understood the solution method, a question which can easily be replied with "yes". In the fourth lesson, however, the teacher asked specific students to summarize solution methods that had been given. In addition, steps that were unclear to students were made the subject of a discussion. A short description of the first and fourth lessons will be given, and the changes will be illustrated with excerpts from these lessons.

Lesson 1 During the first lesson, Anna attempted to orchestrate classroom discourse concerning students' various solution methods for the first time. The students were presented with a problem which involved calculating the distance between a point and a line in the Cartesian coordinate system.

Problem 1: Calculate the distance from point $P(6,1)$ to line $l: y=\frac{1}{3} x+4$.

During classroom discourse, the teacher stood in front of the class, and one by one, students were asked to share their solution method while seated at their own desks. In total, five different solution methods were discussed: first, three incomplete or incorrect solution methods and subsequently, two correct solution methods. Excerpt $1.1^{3}$ presents the beginning of the discourse. Aad was the first student to be asked to share his solution method.

\footnotetext{
3 Excerpts are numbered according to lesson and time. Excerpts 1.1, 1.2, and 1.3 are from the first lesson and are in chronological order. Excerpts 4.1, 4.2, and 4.3 are from the fourth lesson, and they, too, are in chronological order.
} 


\section{Excerpt 1.1}

1 T: Aad, how would you handle this problem?

OPI

[...]

2 Aad: I inserted the point.

ssm

T: You inserted $(6,1)$ ?

CPD

Aad: Yes I put the six into the formula.

T: Yes?

tlr

Aad: So it was one-third times six plus four.

ENC

That is the same as two plus four, which equals six.

7 T: Yes. One-third times six plus four equals six. Yes.

ssm

So then you have the point $(6,6)$ which lies here on the line.

REF

$\begin{array}{lll}8 & \text { Aad: Yes, and that is five units upwards. Because the point is }(6,1) . & \text { ssm } \\ 9 & \text { T: Yes, okay. That is more a distance. } & \text { SEA }\end{array}$

We are looking for the distance, which is a difference in nuance,

the distance is always the shortest distance.

10 T: So I want it like this. [shows on the board]

DEM

Because that is shorter than what you have.

Aad: Yes.

T: Yes, okay? First... [points to Casper, who had raised his hand]

tlr

Casper: No, I also wanted to say that we needed the shortest distance but you already say that. ext

Anna's reaction to Aad's incomplete solution method was to set the idea aside and demonstrate what she meant by distance (lines 9 and 10). However, it remains unclear whether Aad thought he was finished, and whether he would be able to continue his solution method. Instead of investigating this by asking questions or asking other students to react, the teacher chose to set the idea aside. In the following excerpt, in which the third solution method is shared by Emmanuelle, something similar happened

\section{Excerpt 1.2}

Emmanuelle: Well, can't you, like, use Pythagoras' theorem?

$\mathrm{T}$ : Yes, fine, we will need it either way.

T: But if you want to do Pythagoras' theorem here, how will you...

Let me call this point $\mathrm{S}$. This one... Aad, I'll remove your point, yes?

$5 \quad$ Emmanuelle: But you will need that point, right?

tlr

Because you have... Well, you have the hypotenuse, you have to calculate that.

T: But, yes... And how?

ENC

Emmanuelle: Uh, no... wait a second.

T: You have to calculate the hypotenuse, so you have...

Emmanuelle: No, that is not the hypotenuse.

ssm

The hypotenuse is the point that Aad said. That line.

Because you know its length. And you can...

10 T: This one? Do you know its length?

CPD

Emmanuelle: Yes, I think you can...

It's right in the middle of that point... of those two points,

so that is one-and-a-half, I would say.

Well, I am not sure, sorry. I thought I would just say something.

But you can feel that in your story the uncertainty is the four-and-a-half, right?

That doesn't feel completely right. [moves on to the next solution method]

Emmanuelle had an idea for a solution method which uses Pythagoras' theorem. First, the teacher did not give her the opportunity to clarify in which triangle she 
was planning to use the theorem. Then it became clear that she wanted to use the distance five, which was calculated by Aad (Excerpt 1.1), as the length of one of the legs. Emmanuelle shared her idea of finding the length of the other leg (line 11). These are steps that can lead to a genuine solution method. However, instead of investigating the solution method further, the teacher set Emmanuelle's idea aside. The fourth solution method was correct and made use of the circle as the set of points with equal distance to a point. When the solution method had been completed, the teacher reacted by confirming the method, and then moved on to the next solution method. The fifth solution method was to first find the intersection $S$ of line $l$ and the perpendicular line $k$ that passes through $P$, and then to calculate the distance between $P$ and $S$. This is the standard method, as presented in most Dutch textbooks. One student had the idea, and two other students were involved in carrying out the calculations (see Excerpt 1.3. below). Again, the teacher reacted by confirming and moving on.

Lesson 4 The fourth and last lesson of this study took place almost four months later, while the teacher and students were working on a chapter regarding vectors. In preceding lessons, vectors had been defined and vector equations for lines had been discussed. The students were asked to solve the following problem.

Problem 4: Let $l$ be the line given by the following vector equation:

$$
\left(\begin{array}{l}
x \\
y
\end{array}\right)=\left(\begin{array}{l}
3 \\
2
\end{array}\right)+\lambda\left(\begin{array}{c}
4 \\
-1
\end{array}\right)
$$

We consider the lines $a x+2 y=c$, where $a$ and $c$ are constants.

Calculate for which values of $a$ and $c$, the line goes through point $P\left(1,5 \frac{1}{2}\right)$ and perpendicular to $l$.

This problem was chosen so that students would grapple with different representations of lines, and switch between these representations. Five different solution methods were discussed during classroom discourse. The teacher selected four students to present their methods in front of the class. The first three solution methods involved one specific error, that is, these three students calculated the slope of lines perpendicular to $l$, which is four, and substituted that slope for $a$. From their explanations it was clear that the reason for this error was that they were used to the standard form $y=a x+b$, where $a$ is the slope.

After the first student had finished explaining his solution method (which included the error), the teacher asked another student to repeat the method. What happened next is illustrated in the following excerpt 


\section{Excerpt 4.1}

T: Yes, okay. Carolien, can you repeat this? Yes probably, let's hear it.

EXD

Carolien: No, I don't understand.

T: What don't you understand?

eva

Carolien: Yeah, just how he did it.

REC

$[\ldots]$

T: And then?

eva

Carolien: And then suddenly it's four $x$ plus two $y$ equals $c$.

ENC

T: Well, just ask him.

Carolien: That is just substituting, right?

paa

EXD

However, I don't really see where it's coming from.

que

Joris: I think that is on the paper.

paa

Carolien: Yeah, okay.

T: On the paper it says...

CPD

Carolien: $a x+2 y=c$

tlr

T: Yes?

Joris: Yes, and then you have to find out what $a$ and $c$ are.

ENC

So I thought I would just substitute, and then $a$ is four.

paa

I already had that, and then you can substitute it and rewrite it in $y$ is...

and then $a$ is negative two, still...

15 Carolien: Yes?

16 Joris: Yes.

17 Carolien: Okay, yes.

18 T: Does everybody agree?

EXG

[...]

19 T: And then you have something different?

OPI

Alice: Yes, then I have, let me see, how can I explain this...

paa

T: Okay, very difficult, let's say it like this:

I agree up till here [points to calculation of the slope four], and after that I think it's not completely going well.

But we will come back to it later.

First I want to hear the other methods before

I give a guiding question to say why I don't think it's right from there.

The teacher chose not to evaluate Joris' solution method and reveal the error, but instead she asked another student, Carolien, to repeat the method. Carolien pointed out that she did not understand where the "four" came from. Joris explained that he had already found that $a$ equals four and therefore was able to substitute four in the formula $a x+2 y=c$. Carolien seemed to be convinced (line 17). The teacher still refrained from evaluation, instead asking whether other students agreed. Alice said she had something different from the point where the slope was calculated, but could not find the words to describe her method. The teacher decided to set Joris' method aside from the point where the slope was calculated, but did not correct the error. Instead, she moved on to two other solution methods, which involved the same error. The error remained unsolved until the end of the lesson.

The fourth solution method, which was presented by Inez, did not involve the error and was almost correct. She wrote down a vector equation for the line, which can be done right away. Then she changed both the vector equation and $a x+2 y=c$ to the standard form, and continued to calculate $a$ and $c$. In the last step of her solution method she made a calculation error. After Inez was done explaining her method, the teacher asked another student, Thom, to react. Thom said he did not quite understand how Inez got to the vector one four. Excerpt 4.2 presents the discourse that followed. 


\section{Excerpt 4.2}

T: And how did you find that one four $\left[\left(\begin{array}{l}1 \\ 4\end{array}\right)\right]$ ?

REX

Inez: Well, it has to be reversed so you turn them around.

T: Why does it have to be reversed?

Inez: Well, because it is perpendicular.

$\mathrm{T}$ : Okay, but the reverse of four negative one and one four,

I don't think that's the reverse. Do you?

Other students: No.

Inez: Well, then I just don't know what I did.

$\mathrm{T}$ : Yes, did you...?

Thom: You can make it into a fraction, then it becomes

four above negative one and one above four,

and together that becomes negative one.

$\mathrm{T}$ : Together how?

paa

REC

$\exp$

by negative one becomes negative four

EXG

[....]

T: Shall we ask if Carolien can help you?

EXD

Marcel: Yes, please.

tlr

Carolien: Well, in the first case you have a slope of negative zero point two five.

That is four steps to the right and one down.

T: Yes.

Carolien: And you have to multiply that...

the new slope multiplied by that has to be negative one,

so you find four, so that means one step to the right is four steps upward,

so one-fourth, well one four.

T: Yes, okay. Can you follow her? Joris? What she explains?

EXD

It becomes apparent that after Inez had explained her solution method the teacher did not move on, but instead asked for explanations and asked other students to react. After Joris' reaction, the teacher returned to convergent actions, repeating Carolien's explanation and demonstrating another explanation. Finally, a fifth student explained his solution method, which was similar to the first three methods but did not involve the error, and several students were asked to react.

To summarize, a substantial change can be perceived in the way the teacher dealt with both correct and incorrect solution methods. In the first lesson, she reacted by setting aside or confirming, whereas in the fourth lesson, she made the solution methods the subject of discussion by getting other students to react.

\subsubsection{Distribution of Turns}

Important criteria of classroom discourse include that students share their ideas and make their thinking public, are involved in the discussion, and try to follow each other's reasoning. Therefore, we have investigated the distribution of turns among the teacher and students, and the ways in which the teacher regulated the distribution of turns. In our quantitative analysis, we found that the number of students involved in the discourse increased from nine in the first lesson to 18 in the fourth (see Fig. 2). We also found that the teacher spoke more than all students combined during the first lesson and spoke less than the students during the other lessons, as portrayed in Fig. 3. Getting students to react to each other by asking other students to react is 
something that happened only three times in the first lesson, but 29 times in the fourth lesson (for example: "Shall we ask Carolien to help you?"). Furthermore, during the first lesson the teacher did not articulate rules for classroom discourse, whereas she did in subsequent lessons, for example by saying "I want you to listen" or "Why don't you ask him if you don't understand?". In addition, further analysis showed that the patterns of interaction changed from one-on-one dialogues between the teacher and a single student, toward patterns that involved more students alternating turns.

In all three excerpts from the first lesson (Excerpt 1.3 follows below), the teacher interacted about a solution method with only one student. In Excerpt 1.1 from the first lesson, Casper had raised his hand to react to Aad. However, the teacher already reacted before giving Casper the opportunity to respond ("Casper: No, I also wanted to say that we needed the shortest distance but you already said that"). In Excerpt 1.2, the teacher and Emmanuelle alternated turns and no one else was asked to react.

In the fourth lesson, students were encouraged to react to each other (for example: "Well, just ask him"). In Excerpt 4.1, various students talked and reacted to each other's ideas. From line 8 until line 17, two students even talked to each other instead of talking to the teacher. Excerpt 4.2 also shows various students alternating turns and reacting to each other. Only Excerpt 4.3, from the end of the lesson, which follows below, clearly shows interaction between the teacher and a single student.

In summary, the distribution of turns shifted from sequences of interaction between the teacher and one student in the first lesson, toward the teacher getting students to react to each other and various students alternating turns in the fourth lesson.

\subsubsection{Teacher Actions}

In Fig. 4 as well as in the excerpts above, a shift can be recognized in the teacher's actions from convergent, teacher-led actions toward divergent, student-led actions.

In the first lesson, the number of convergent teacher actions was much higher than the number of divergent teacher actions. The most frequent teacher action was closed progress details. Excerpt 1.3 is from the first lesson and regards the fifth solution method (see 3.4.1.). The teacher asks Sasha to help in finding the equation for line $k$.

\section{Excerpt 1.3}

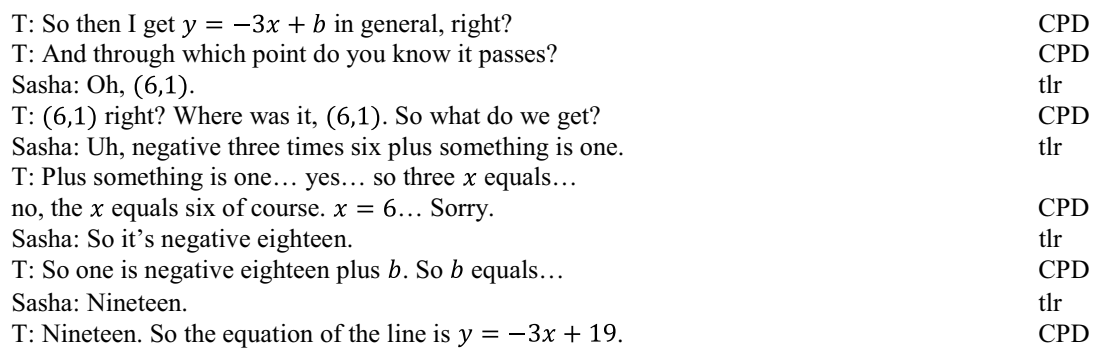


The teacher actions in this excerpt are all closed progress details alternated with teacher-led responses. Drageset (2015) found that closed progress details often appear in sequences, alternating with teacher-led responses. The second most frequent teacher action in the first lesson was reformulate, which mostly occurred when the teacher tried to repeat the steps of a solution method on the whiteboard. For example, in Excerpt 1.1, line 7: "Yes. One third times six plus four equals six. Yes. So then you have the point $(6,6)$ which lies here on the line". Furthermore, the teacher requested very few clarifications or explanations, while often a request to explicate students' thinking would have been appropriate. For example, in Excerpt 1.2, the teacher did not ask how Emmanuelle wants to use Pythagoras' theorem, instead starting by choosing a triangle.

In the fourth lesson, divergent teacher actions were more frequent than convergent teacher actions. This is illustrated by both Excerpts 4.1 and 4.2, in which the teacher's actions were often external, and intended to prompt other students to react, or they were requests, intended to prompt students to explain or clarify their thinking-for example, "Why does it have to be reversed?" and "Together how?".

As shown in Fig. 4, over the course of the first three lessons the number of converging actions decreased and the number of divergent actions increased. However, a slight break in this trend appeared between the third and fourth lessons. In particular, the closed progress details increased again, and a demonstration was given by the teacher. Excerpt 4.3 presents the discourse at the end of the fourth lesson, when the teacher tried to solve the error regarding the use of the letter $a$.

\section{Excerpt 4.3}

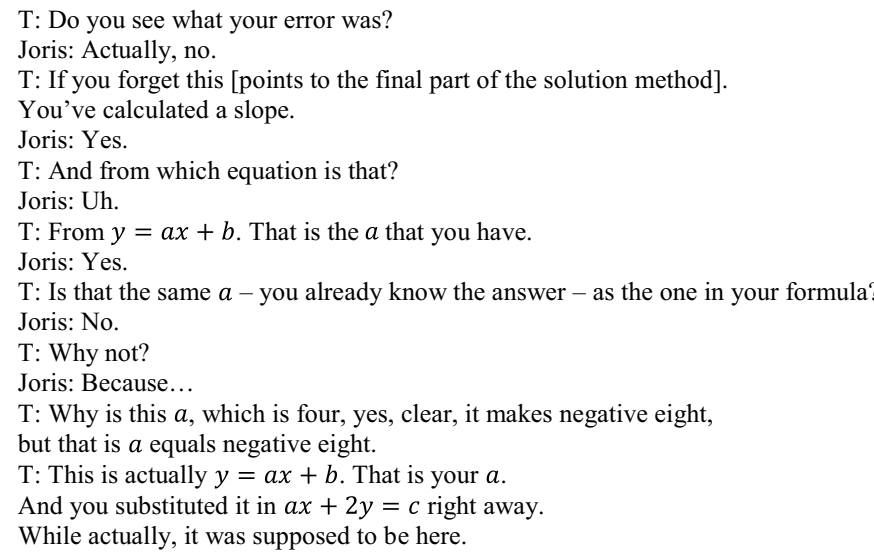

And you substituted it in $a x+2 y=c$ right away.

In this excerpt, the teacher's actions were mostly closed progress details. Apparently, after repeatedly using divergent actions and trying to let the students solve the error, the teacher returned to using convergent actions, and eventually chose to demonstrate the different uses of the letter $a$. 
To summarize, the teacher's actions shift from mainly convergent, teacher-led actions in the first lesson, to mainly divergent, student-led actions in following lessons.

\section{Conclusion and Discussion}

The aim of this study was to investigate the teacher's role in classroom discourse about students' various solution methods in higher secondary mathematics education. In collaboration with the teacher, four lessons in analytic geometry were developed. Video recordings of classroom discourse were analyzed to answer the two research questions. This resulted in a framework for analyzing classroom discourse and a description of the changes in the teacher's role in classroom discourse.

\subsection{Framework}

To answer our first research question, a framework was developed to characterize teacher actions during mathematical classroom discourse. The framework was developed during data analysis, and combines aspects of two existing frameworks, those of Drageset (2015) and Henning et al. (2012), as well as the data of this study. The framework by Drageset (2015) categorizes teacher and student actions during classroom discourse in order to investigate patterns in interactions between students and teacher. The categorization was particularly useful for our analysis, as our aim was also to categorize teacher and student actions with regard to their discourse contribution. Whereas Drageset's framework focusses specifically on the types of turns, we also took into account the content of utterances. Our categorization in convergent, divergent, encouraging, and regulating actions was partially based upon the framework of Henning et al. (2012, p. 495), which presents comparisons between convergent, teacher-led, and divergent, student-led participant frameworks. Henning et al. compare two types of participant frameworks that are regarded as either convergent or divergent, and categorize each teacher action as belonging to one of the two types. In contrast, our framework regards each teacher action as divergent or convergent in and of itself, depending on its specific contribution to the discourse, and whether it serves to build further on student ideas or serves to take control over the subject of discourse.

Our framework is a useful tool that can be applied by researchers, teachers, and teacher-educators as they analyze or develop classroom discourse, in particular classroom discourse concerning various solution methods. Since our framework was developed by analyzing a teacher's first steps in orchestrating classroom discourse, and since the collaboration with Anna was focused especially on "getting students to talk", the framework may be especially useful for studies that focus on teachers' beginning process of developing a discourse community and establishing favorable norms within their lessons. 


\subsection{Changes in the Teacher's Role in Classroom Discourse}

To answer our second research question, we identified three main aspects of change in the teacher's role in classroom discourse. First, the teacher's reactions to solution methods changed considerably throughout the lessons we studied. The teacher's reaction to incomplete or incorrect solution methods changed from setting them aside, to attempting to get other students to determine and solve the mathematical error. The teacher's reaction to a correct solution method changed from confirming and moving on, to encouraging other students to react or summarize the solution method. Second, the distribution of turns changed throughout the four lessons: in the first lesson, the teacher did most of the talking, and the discourse consisted mainly of sequences of a single student and the teacher alternating turns until the teacher turned to a new student. In the other lessons, students talked more, and the patterns of interaction involved more switches between students' turns, so the discourse became more of a joint conversation. Third, we observed a strong shift in the teacher's actions during classroom discourse. In the first lesson, most teacher actions were convergent, and the teacher had control over the subject of discussion. Gradually, the teacher tried to build the discussion on student ideas, using more divergent actions.

The changes as described above do seem to contribute to the development of a discourse community. In later lessons, students talked more and alternated turns, so that the discourse became more of a whole-class discussion. This suggests a growing participation of students. Naturally, numbers of words and talking by students only provide an indication of active participation, because these numbers do not give insight into the content of students' contributions, and participation can also be in the form of listening without talking (O'Connor et al. 2017). However, in combination with the other aspects of change, these numbers point to a development of patterns of interaction that are associated with "good" classroom discourse. The patterns of interaction shifted away from patterns in which the teacher alternates turns with a single student and does most of the thinking, such as the "initiation-responseevaluation" pattern (Cazden 2001), or alternations between closed progress details and teacher-led responses, as described by Drageset (2015). This trend indicates the shifting away from teacher-centered patterns of classroom discourse and toward building the discussion on students' thinking. By making each solution method a subject of discussion, instead of evaluating and moving on, the teaching moves away from practices in which the teacher holds the authority over the right answer, toward collectively establishing truth based on logical argumentation. Asking students to evaluate solution methods gives students authority over the mathematical work and holds students accountable to the community of learners, which fosters disciplinary engagement (Engle and Conant 2002). The use of less convergent actions and more divergent actions is a strong indication for building the discussion on students' ideas and reasoning, because our categorization in convergent and divergent teacher actions is based upon the distinction between teacher actions that serve to control the subject of discussion, or those that serve to build further on student ideas. Several divergent teacher actions that we have identified can be regarded as "talk moves" that 
promote student thinking, such as orienting to the thinking of others, and clarifying and sharing their own thoughts (Michaels and O'Connor 2015).

Students' participation, building the discourse on students' ideas, and logical argumentation are important criteria of classroom discourse but do not ensure students' learning of mathematics. Productive classroom discourse entails discussing connections, similarities, and differences between solution methods, in order to support students in developing mathematical ideas and guiding students toward important disciplinary ideas (Stein et al. 2008). Whereas Anna did increasingly succeed in building the discussion on students' ideas, she struggled with making different solution methods the subject of discussion, and in helping students make connections between the different solution methods. This may have been related to the subject, analytic geometry, which was new for her. Developing classroom discourse further toward productive classroom discourse would require more mathematical work in the sense of anticipating student responses, monitoring student ideas, and selecting students to contribute (Ball 2017; Stein et al. 2008). In conclusion, the teacher has made important steps toward the development of classroom discourse, but establishing a productive discourse community would require additional changes and development.

This conclusion is consistent with previous research that shows that developing productive classroom discourse is a complex and long-term process (e.g., HufferdAckles et al. 2004; Nathan and Knuth 2003). Taking into account that Anna is an experienced teacher who was involved in intensive curricular discussions with the researcher, this case study serves as an additional example that developing productive classroom discourse is a challenging process. The four lessons described in this study were enacted over a period of almost four months. In the regular lessons that took place between these four lessons, Anna did not plan whole-class discussions concerning students' various solution methods. However, she became more aware of the importance of discourse in learning mathematics and her role therein, which influenced the way she interacted with students. However, her activities regarding the development of classroom discourse, and reflecting on her actions in classroom discourse, were limited to the four lessons in this study. We have shown that it was possible for Anna to take important steps in developing classroom discourse throughout these four lessons. Certain aspects of Anna's particular context make this finding a worthy addition to research in the field. Previous studies have shown the development of classroom discourse in primary or lower secondary school in longitudinal projects of intensive professional development or with teachers who are highly skilled with regard to classroom discourse (e.g., Leinhardt and Steele 2005; McClain and Cobb 2001). In our study, classroom discourse about various solution methods was a new practice for Anna and her students, yet considerable changes took place throughout the four lessons. An additional challenge was the Dutch teachers' reliance on textbooks (Blockhuis et al. 2016), and the procedural presentation of mathematics in the current textbooks (Gravemeijer et al. 2016). This presented Anna with a group of students that had experienced ten years of outcome-oriented mathematics lessons that did not involve whole-class discussions about various student ideas and solution methods. In addition, analytic geometry was a new subject for Anna as well as for her students. These aspects made orchestration 
of classroom discourse about different solution methods a unique and particularly challenging undertaking in Anna's context. The description of the changes in the teacher's role during classroom discourse in Anna's context provides us with new insights into mathematical classroom discourse in higher secondary education.

Several characteristics of the collaborative development of these four lessons can be identified as contributing to the changes in the teacher's role in classroom discourse. For example, the collaboration between Anna and the researcher was based upon a shared goal, summarized as "getting students to share and discuss different solution methods". This shared goal, and the iterative nature of development, made the collaboration a joint learning experience, which undoubtedly influenced the changes in the teacher's practice. Furthermore, the collaboration meets several known criteria for effective teacher professional development, as reported on by Darling-Hammond et al. (2017): content-focus, active learning, collaboration, coaching and expert support, feedback and reflection. The development was content-focused on analytic geometry and in particular on how to teach it. The iterative process of development in design cycles (design, enactment, evaluation) ensured active learning and realized sustained duration. Anna's collaboration with the researcher included aspects of both teacher collaboration, and coaching and expert support. The researcher's role varied from interested fellow mathematics teacher, to didactical coach, to scholar with theoretical knowledge on classroom discourse. These different roles can be regarded as a particular strength of this case study, as the researcher was able to adapt to changing situations, to have a sense of realism about the classroom situation, and to build access, empathy, and trust, which Cohen et al. (2011) describe as important qualities of a case study researcher. Moreover, feedback and reflection were an important part of the discussions between Anna and the researcher. In particular, the use of video-based feedback is known to have a possible strong effect on teacher change (e.g., Gaudin and Chaliès 2015; Karsenty and Sherin 2017). In addition, the teacher's openness to feedback and "will to learn" (Van Eekelen et al. 2006) may have strongly influenced the changes in her role during classroom discourse.

Depending on each individual context, an important question remains concerning how to support teachers in developing classroom discourse about different solution methods. Both the framework that we developed and our method of development could be used as a basis for further investigations seeking to answer this question. In this study, we explicitly investigated the first steps in developing classroom discourse. Further research is needed to see whether a productive and sustainable discourse community can be established over a longer period of time. Importantly, students were not explicitly taken into account in this study. We have presumed that the role of students in discourse and the ways in which students articulate their mathematical thinking also change during the teacher's development of a discourse community. Additional research is necessary to see in which ways the students benefit from changes in the teacher's role. For example, future research could investigate students' actions during classroom discourse, and how these actions relate to their mathematical thinking. Further research with a larger sample of teachers is also necessary to investigate what works for teachers in collaboratively developing problem-based lessons and in orchestrating classroom discourse about students' various 
solution methods. Since we now know that it is possible to take important steps toward productive classroom discourse in one higher secondary school classroom, the next step is to delineate the needs of mathematics teachers in establishing a discourse community, and to investigate the ways in which students benefit from such a community.

Open Access This article is distributed under the terms of the Creative Commons Attribution 4.0 International License (http://creativecommons.org/licenses/by/4.0/), which permits unrestricted use, distribution, and reproduction in any medium, provided you give appropriate credit to the original author(s) and the source, provide a link to the Creative Commons license, and indicate if changes were made. 


\section{Appendix}

\section{Code Manual}

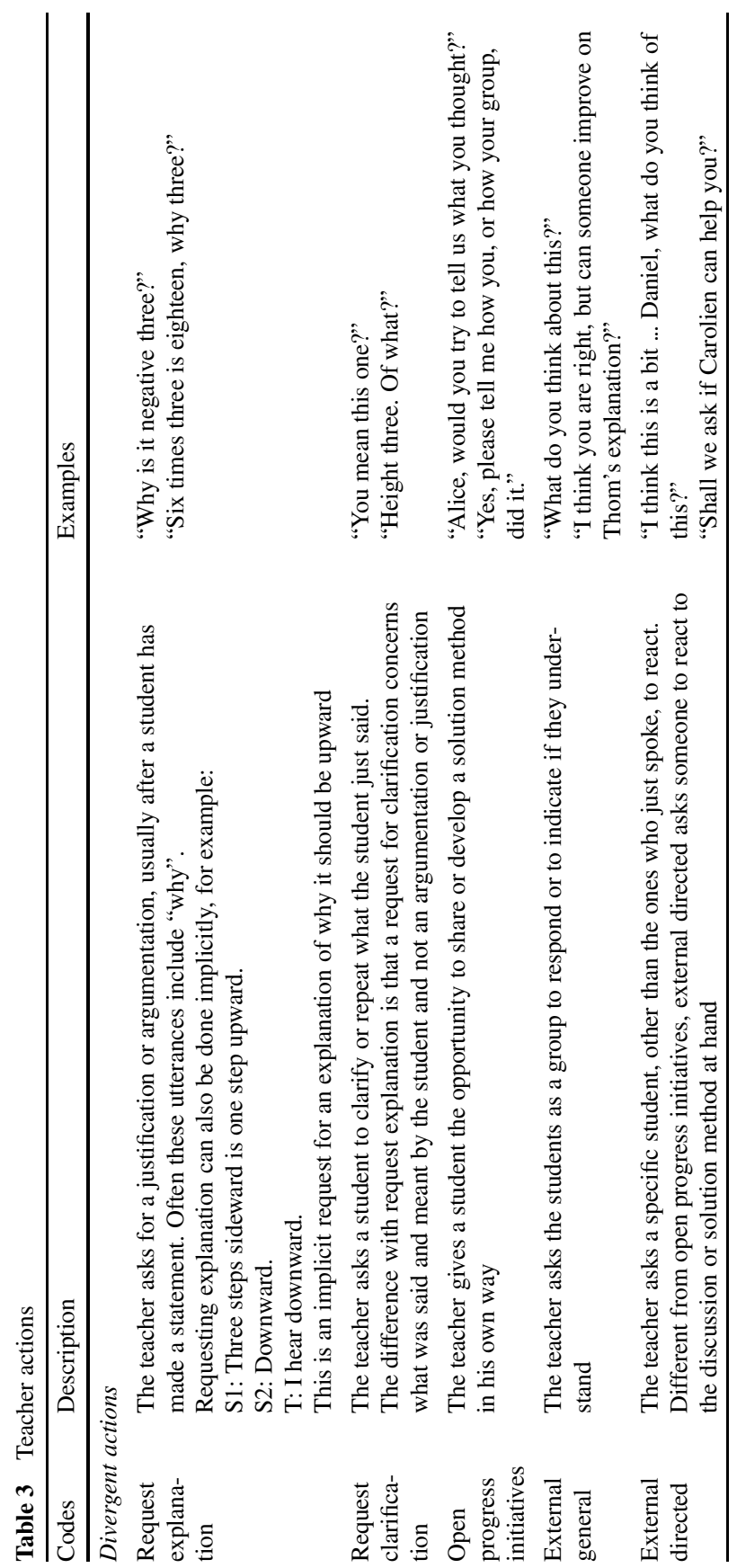




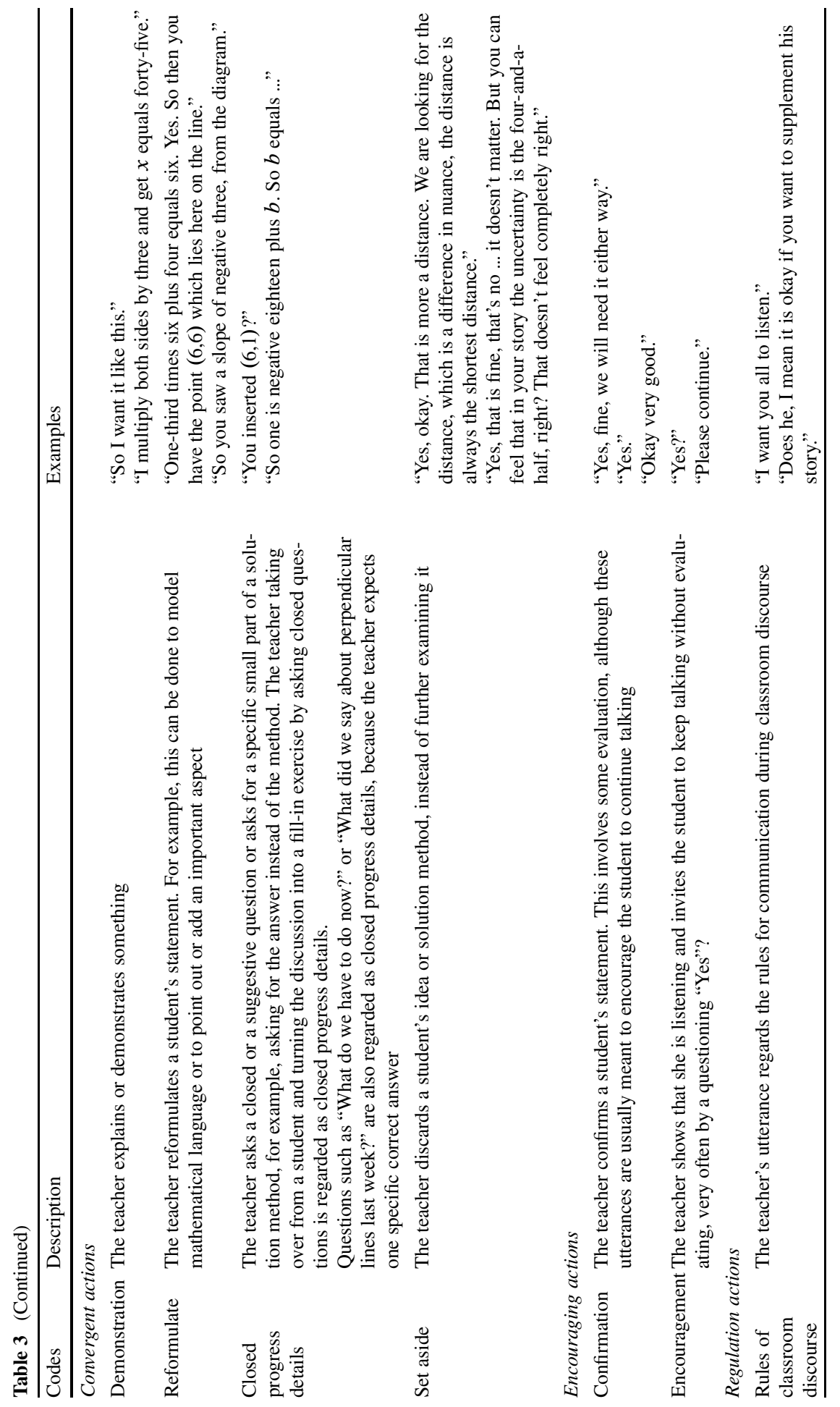




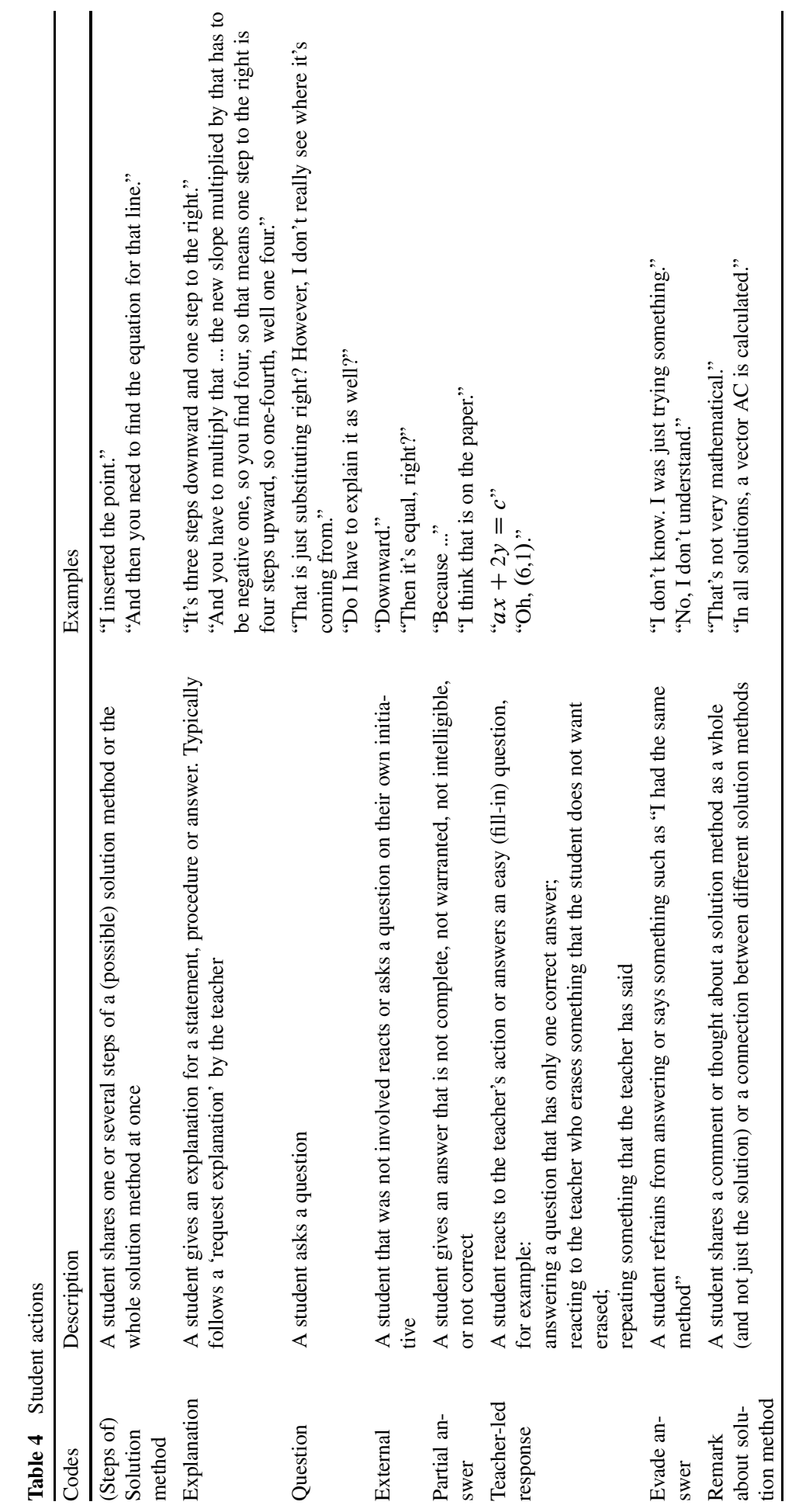




\section{References}

Ball, D. L. (2017). Uncovering the special mathematical work of teaching. In G. Kaiser (Ed.), Proceedings of the 13th International Congress on Mathematical Education. ICME-13 Monographs. (pp. 11-35). https://doi.org/10.1007/978-3-319-62597-3.

Ball, D. L., Thames, M.H., \& Phelps, G. (2008). Content knowledge for teaching: what makes it special? Journal of Teacher Education, 59(5), 389-407. https://doi.org/10.1177/0022487108324554.

Blockhuis, C., Fisser, P., Grievink, B., \& Voorde, T.M. (2016). Leermiddelenmonitor (report on teaching materials) 15/16. Enschede: SLO.

Cazden, C.B. (2001). Classroom discourse: the language of teaching and learning. Vol. 2. Portsmouth: Heinemann.

Cengiz, N., Kline, K., \& Grant, T.J. (2011). Extending students' mathematical thinking during wholegroup discussions. Journal of Mathematics Teacher Education, 14(5), 355-374. https://doi.org/10. 1007/s10857-011-9179-7.

Cobb, P., Confrey, J., DiSessa, A., Lehrer, R., \& Schauble, L. (2003). Design experiments in educational research. Educational Researcher, 32(1), 9-13. https://doi.org/10.3102/0013189x032001009.

Cobb, P., Wood, T., \& Yackel, E. (1993). Discourse, mathematical thinking, and classroom practice. In E. A. Forman, N. Minick \& C. A. Stone (Eds.), Contexts for learning: Sociocultural dynamics in children's development (pp. 91-119). Oxford: Oxford University Press.

Cohen, L., Manion, L., \& Morrison, K. (2011). Research Methods in Education. New York, NY: Routledge

Darling-Hammond, L., Hyler, M.E., \& Gardner, M. (2017). Effective teacher professional development. Palo Alto: Learning Policy Institute.

Drageset, O.G. (2014). Redirecting, progressing, and focusing actions-a framework for describing how teachers use students' comments to work with mathematics. Educational Studies in Mathematics, 85(2), 281-304. https://doi.org/10.1007/s10649-013-9515-1.

Drageset, O.G. (2015). Student and teacher interventions: a framework for analysing mathematical discourse in the classroom. Journal of Mathematics Teacher Education, 18(3), 253-272. https://doi.org/ 10.1007/s10857-014-9280-9.

Engle, R. A., \& Conant, F. R. (2002). Guiding principles for fostering productive disciplinary engagement: explaining an emergent argument in a community of learners classroom. Cognition and Instruction, 20(4), 399-483. https://doi.org/10.1207/S1532690XCI2004_1.

Gaudin, C., \& Chaliès, S. (2015). Video viewing in teacher education and professional development: a literature review. Educational Research Review, 16, 41-67.

Gravemeijer, K., Bruin-Muurling, G., Kraemer, J.-M., \& Van Stiphout, I. (2016). Shortcomings of mathematics education reform in the Netherlands: a paradigm case? Mathematical Thinking and Learning, 18(1), 25-44. https://doi.org/10.1080/10986065.2016.1107821.

Güçler, B. (2016). Making implicit metalevel rules of the discourse on function explicit topics of reflection in the classroom to foster student learning. Educational Studies in Mathematics, 91(3), 375-393. https://doi.org/10.1007/s10649-015-9636-9.

Heinze, A., Star, J. R., \& Verschaffel, L. (2009). Flexible and adaptive use of strategies and representations in mathematics education. ZDM Mathematics Education, 41(5), 535-540. https://doi.org/10.1007/ s11858-009-0214-4.

Henning, J.E., McKeny, T., Foley, G. D., \& Balong, M. (2012). Mathematics discussions by design: creating opportunities for purposeful participation. Journal of Mathematics Teacher Education, 15(6), 453-479. https://doi.org/10.1007/s 10857-012-9224-1.

Herbel-Eisenmann, B., Meany, T., Pierson Bishop, J., \& Heyd-Metzuyanim, E. (2017). Highlighting heritages and building tasks: a critical analysis of mathematics classroom discourse literature. In J. Cai (Ed.), Compendium for research in mathematics education (pp. 722-765). Reston: National Council of Teachers of Mathematics.

Hufferd-Ackles, K., Fuson, K. C., \& Sherin, M. G. (2004). Describing levels and components of a mathtalk learning community. Journal for Research in Mathematics Education, 35(2), 81-116.

Karsenty, R., \& Sherin, M.G. (2017). Video as a catalyst for mathematics teachers' professional growth. Journal of Mathematics Teacher Education, 20(5), 409-413. https://doi.org/10.1007/s10857-0179387-x.

Lampert, M. (1990). When the problem is not the question and the solution is not the answer: mathematical knowing and teaching. American Educational Research Journal, 27(1), 29-63.

Leinhardt, G., \& Steele, M.D. (2005). Seeing the complexity of standing to the side: instructional dialogues. Cognition and Instruction, 23(1), 87-163. https://doi.org/10.1207/s1532690xci2301_4. 
Levav-Waynberg, A., \& Leikin, R. (2012). The role of multiple solution tasks in developing knowledge and creativity in geometry. Journal of Mathematical Behavior, 31(1), 73-90. https://doi.org/10.1016/ j.jmathb.2011.11.001.

McClain, K., \& Cobb, P. (2001). An analysis of development of sociomathematical norms in one firstgrade classroom. Journal for Research in Mathematics Education, 32(3), 236-266. https://doi.org/ 10.2307/749827.

Mehan, H. (1979). Learning lessons: social organization in the classroom. Cambridge: Harvard University Press.

Mercer, N., \& Sams, C. (2006). Teaching children how to use language to solve maths problems. Language and Education, 20(6), 507-528. https://doi.org/10.2167/le678.0.

Michaels, S., \& O'Connor, C. (2015). Conceptualizing talk moves as tools: professional development approaches for academically productive discussions. In Socializing intelligence through talk and dialogue (pp. 333-347). https://doi.org/10.3102/978-0-935302-43-1_27.

Michaels, S., O’Connor, C., \& Resnick, L.B. (2008). Deliberative discourse idealized and realized: accountable talk in the classroom and in civic life. Studies in Philosophy and Education, 27(4), 283-297. https://doi.org/10.1007/s11217-007-9071-1.

Murata, A., Siker, J., Kang, B., Baldinger, E. M., Kim, H.-J., Scott, M., \& Lanouette, K. (2017). Math talk and student strategy trajectories: the case of two first grade classrooms. Cognition and Instruction, 35(4), 290-316. https://doi.org/10.1080/07370008.2017.1362408.

Nathan, M.J., \& Knuth, E.J. (2003). A study of whole classroom mathematical discourse and teacher change. Cognition and Instruction, 21(2), 175-207. https://doi.org/10.1207/S1532690XCI2102_03.

O'Connor, C., Michaels, S., Chapin, S., \& Harbaugh, A. G. (2017). The silent and the vocal: participation and learning in whole-class discussion. Learning and Instruction, 48, 5-13. https://doi.org/10.1016/ j.learninstruc.2016.11.003.

Polya, G. (1957). How to solve it (2nd edn.). Stanford: Stanford University. https://doi.org/10.2307/ 3609122 .

Richards, J. (1991). Mathematical discussions. In E. von Glasersfeld (Ed.), Radical constructivism in mathematics education (pp. 13-51). Dortrecht: Kluwer Academic Publishers.

Ryve, A. (2011). Discourse research in mathematics education: a critical evaluation of 108 journal articles. Journal for Research in Mathematics Education, 42(2), 167-199.

Saldaña, J. (2016). The coding manual for qualitative researchers. Los Angeles: SAGE.

Schoenfeld, A.H. (1985). Mathematical problem solving. Orlando: Academic Press.

Scott, P.H., Mortimer, E.F., \& Aguiar, O.G. (2006). The tension between authoritative and dialogic discourse: a fundamental characteristic of meaning making interactions in high school science lessons. Science Education, 90(4), 605-631. https://doi.org/10.1002/sce.20131.

Sfard, A. (2008). Thinking as communicating: human development, the growth of discourses, and mathematizing. New York: Camebridge Universtity Press. https://doi.org/10.1017/CBO9780511499944.

Sfard, A., Nesher, P., Streefland, L., Cobb, P., \& Mason, J. (1998). Learning mathematics through conversation: is it as good as they say? For the Learning of Mathematics, 18(1), 41-51.

Sherin, M.G. (2002). A balancing act: developing a discourse community in a mathematics classroom. Journal of Mathematics Teacher Education, 5(3), 205-233. https://doi.org/10.1023/a:1020134209073.

Shulman, L. S. (1986). Those who understand: knowledge growth in teaching lee. Educational Researcher, 15(2), 4-14.

Smith, M.S., \& Stein, M.K. (2018). 5 practices for orchestrating productive mathematics discussions. Reston: National Council of Teachers of Mathematics.

Speer, N. M., \& Wagner, J.F. (2009). Knowledge needed by a teacher to provide analytic scaffolding during undergraduate mathematics classroom discussions. Journal for Research in Mathematics Education, 40(5), 530-562. https://doi.org/10.2307/40539355.

Star, J.R., \& Verschaffel, L. (2017). Providing support for student learning: recommendations from cognitive science for the teaching of mathematics. In J. Cai (Ed.), Compendium for research in mathematics education (pp. 292-307). Reston: National Council of Teachers of Mathematics.

Stein, M. K., Engle, R. A., Smith, M.S., \& Hughes, E. K. (2008). Orchestrating productive mathematical discussions: five practices for helping teachers move beyond show and tell. Mathematical Thinking and Learning, 10(4), 313-340. https://doi.org/10.1080/10986060802229675.

Van Eekelen, I. M., Vermunt, J.D., \& Boshuizen, H. P. A. (2006). Exploring teachers' will to learn. Teaching and Teacher Education, 22(4), 408-423. https://doi.org/10.1016/j.tate.2005.12.001.

Van Zoest, L.R., Stockero, S.L., Leatham, K.R., Peterson, B.E., Atanga, N.A., Ochieng, M. A., et al. (2017). Attributes of instances of student mathematical thinking that are worth building on in 
whole- class discussion. Mathematical Thinking and Learning, 19(1), 33-54. https://doi.org/10.1080/ 10986065.2017 .1259786$.

Wallach, T., \& Even, R. (2005). Hearing students: the complexity of understanding what they are saying, showing, and doing. Journal of Mathematics Teacher Education, 8(5), 393-417. https://doi.org/10. 1007/s10857-005-3849-2.

Walshaw, M., \& Anthony, G. (2008). The teacher' s role in classroom discourse: a review of recent research into mathematics classrooms. Review of Educational Research, 78(3), 516-551.

Yackel, E., \& Cobb, P. (1996). Sociomathematical norms, argumentation, and autonomy in mathematics. Journal for Research in Mathematics Education, 27(4), 458-477. https://doi.org/10.2307/749877. 